\title{
Navegando em águas raras: notas de uma pesquisa com famílias de crianças e adolescentes vivendo com doenças raras
}

\author{
Navigating in rare oceans: notes from a family survey of children \\ and adolescents living with rare diseases
}

Daniel de Souza Campos (https://orcid.org/0000-0002-8937-7474) ${ }^{1}$

Martha Cristina Nunes Moreira (https://orcid.org/0000-0002-7199-3797) ${ }^{1}$

Marcos Antonio Ferreira do Nascimento (https://orcid.org/0000-0002-3363-4232) ${ }^{1}$

${ }^{1}$ Instituto Nacional de

Saúde da Mulher da Criança

e do Adolescente Fernandes

Figueira, Fundação Oswaldo

Cruz. Av. Rui Barbosa 716,

Flamengo. 22250-020 Rio

de Janeiro RJ Brasil.

daniel.ufano@gmail.com

\begin{abstract}
This article seeks to highlight the construction of social navigation in a hospital. Our focus is to reflect on scenes of application of a questionnaire on family costs of care/treatment of children with rare diseases. These processes are linked to the markers of gender, race, and generation of one of the authors. The interaction between researcher and subjects of field research is socially constructed according to the specific circumstances that demarcate the invitation to participate in the research, as well as data collection. It implies that his position as a researcher and the ethical perspective need to be well defined. The approach and ethics build this social navigation with the hospital and the subjects are permeated by difficulty and uncertainty, but also by surprises and learning. It was possible to observe remarkable characteristics of the institution, of their employees and the families, to evaluate the used methodological strategies.
\end{abstract}

Key words Child, Adolescent, Family costs, Rare diseases
Resumo No presente artigo, procura-se evidenciar a construção da navegação social em um hospital. O enfoque dado privilegiou os bastidores da aplicação de um questionário quantitativo sobre os custos da família com os cuidados/tratamento de seu(sua) filho(a) com doença rara. Permeando a descrição desses processos estão os marcadores de gênero, raça e geração de um dos autores deste artigo. A interação entre pesquisador e sujeitos da pesquisa em campo é socialmente construída, conforme as circunstâncias especificas que demarcam o convite para participar da pesquisa, bem como a coleta de dados, por isso o lugar que ocupa e a postura ética precisam estar bem definidos e claros para o pesquisador. O exercício metodológico e ético de construção desta navegação social com a instituição hospitalar e os sujeitos pesquisados foi permeada por dificuldade e incertezas, mas também por surpresas e aprendizados. Foi possivel observar características marcantes da instituição, de seus funcionários e das famílias entrevistadas e, avaliar as estratégias metodológicas utilizadas. Palavras-chave Criança, Adolescente, Custos familiares, Doenças raras 


\section{Introdução}

O presente artigo alcança os bastidores do trabalho de campo da pesquisa Como são raras essas crianças e adolescentes!. A pesquisa teve dois grandes componentes: (a) um estudo dos custos diretos e indiretos gerados para as famílias após o diagnóstico de uma doença considerada rara e complexa em seu(sua) filho(a); (b) um estudo dos significados do associativismo para as famílias nos itinerários de busca por cuidado e tratamento para seus(suas) filhos(as).

É na etapa da aplicação de um questionário para análise de custos, que ficou sob responsabilidade de um dos pesquisadores da equipe - o mais jovem, negro e do gênero masculino - que as dimensões interacionais mediadas pelos marcadores gênero, geração e raça/cor dinamizaram o instrumento, gerando conversas e permitindo acionar as dimensões da alteridade e da reciprocidade, em um ambiente de ordem negociada ${ }^{1}$. Considerando que aplicar um instrumento não exime o pesquisador de reconhecer a dimensão simbólica da interação, assumimos como relevante refletir sobre: (1) os aspectos pessoais que remetem ao lugar social e de fala de quem conduz um campo de pesquisa; (2) a realização de pesquisas em ambientes institucionais, como um hospital especializado, exige um diálogo nem sempre fácil com suas regulações, no paradoxo de que a autonomia do paciente está regulada pelo espaço institucional e seus poderes; (3) o reconhecimento de que empiricamente o cuidado com pessoas vivendo com doenças raras exige um custo alto de ordem afetiva e social, mas que falar disso por parte de famílias que frequentam hospitais públicos e em sua maioria são de classes trabalhadoras da população pode tornar-se um tema difícil, que exige habilidade afetiva e sensibilidade do pesquisador.

Assim, essa nota de pesquisa visa abordar os aspectos incorporados do "jeitinho"2 para navegar socialmente no espaço institucional, considerando os estranhamentos que essa presença provoca na instituição quando um pesquisador jovem, negro se aproxima das famílias para convidá-las a evocar memórias, fazer contas, enumerar rotinas de cuidado, refletir sobre perdas e ganhos que costumam ser vividas sem muita reflexão no cotidiano. Até porque falar de saúde ou buscar cuidados para a saúde nem sempre combinam com dar-se conta de que faltam muitas vezes recursos de ordem de apoios e de renda para esse cuidado.

A fim de situar o quanto uma condição de saúde rara e complexa compromete e exige na clínica do cuidado a essas crianças e adolescentes por parte da família recorremos a Moreira et al. ${ }^{3}$. Os autores apontam que quando uma condição crônica complexa de saúde é diagnosticada e tratada desde a infância, ela vai passar por transformações que incluem a maneira como se dá o seu fluxo entre os serviços e as mudanças que envolvem processos de alta hospitalar, de tomada de decisão e de construção de redes, incluindo família, hospital, escola e sistema de garantia de direitos. E mesmo com autonomia regulada pela família, crianças e adolescentes são sujeitos ativos nas interações e nos aprendizados, nas interpretações das experiências de viver com uma condição crônica em seu próprio corpo, desenvolvendo estratégias de sociabilidade ${ }^{4,5}$. A dependência de equipamentos para respirar, se locomover e se alimentar, bem como de medicamentos, muitos dos quais de alto custo, nos fazem reconhecer que "seus corpos desafiam a natureza e nos impulsionam, por exemplo, a assumir a complexidade como inerente à sua existência"' ${ }^{\text {"( }}$.7).

Dentro do espectro das condições crônicas complexas de saúde na vida de crianças e adolescentes, existem aquelas que podem ser reconhecidas como doenças raras, e que diferentemente das doenças crônicas mais comuns e prevalentes na infância e adolescência como o diabetes e a asma, elas podem atingir até 65 indivíduos em cada $100.000^{7,8}$. No presente artigo, as famílias de crianças e adolescentes que participaram da pesquisa conviviam com três diagnósticos em seus (suas) filhos(as): Mucupolissacaridoses (MPS), Fibrose Cística (FC) e Osteogênese Imperfeita (OI).

As Mucopolissacaridoses (MPS) são um grupo de doenças lisossômicas causadas pela deficiência de uma das enzimas envolvidas no catabolismo dos glicosaminoglicanos (GAG). Na ausência dessa enzima ocorre um acúmulo intracelular que desencadeia a resposta inflamatória, causando lesão celular/tecidual e a disfunção de órgãos e sistemas ${ }^{9-11}$. Já a Fibrose Cística (FC) é uma doença genética de caráter autossômico recessivo, crônica e progressiva, que atinge vários órgãos e sistemas do organismo. O paciente com FC apresenta secreções mucosas espessas e viscosas, que contribuem para o aparecimento de três características básicas: doença pulmonar obstrutiva crônica, níveis elevados de eletrólitos no suor, insuficiência pancreática com má digestão/ má absorção e consequente desnutrição secundária $^{12}$. Por fim, a Osteogênese Imperfeita (OI) é uma condição potencialmente incapacitante, caracterizada por grande fragilidade óssea, fraturas recorrentes, com deformidades secundárias ${ }^{13}$. 
$\mathrm{Na}$ literatura nacional, são recorrentes as considerações sobre a pouca reflexão produzida em relação à aplicação de questionários em trabalhos de campo ${ }^{14,15}$. Pereira ${ }^{16}$ considera que além da observação de como os itens se comportam, se são de difícil compreensão ou não, pouco se observa sobre o comportamento dos respondentes, suas reações, comunicadas de forma oral ou não, em relação ao instrumento e ao formato da aplicação. E aqui acrescentamos o fato de que pouco ou nada se explora sobre o lugar do pesquisador nas negociações com os participantes da pesquisa, com os lugares onde a pesquisa se desenvolve e sobre suas próprias características pessoais intensificando a reciprocidade na interação. Compreendemos o trabalho de campo como promotor de reflexividade, que merece situar o pesquisador e seus interesses como ferramentas do processo de produção do conhecimento como alerta Rostagnol ${ }^{17}$.

Dessa maneira, nos propomos a lançar um olhar sobre as mediações simbólicas entre pesquisador, participantes e espaço institucional, com vistas a incrementar a reflexividade do processo de pesquisa sobre quanto custa para as famílias ter um(a) filho(a) com uma doença rara.

$\mathrm{O}$ artigo não pretende analisar os resultados do questionário de custos aplicado, mas promover um diálogo sobre os bastidores que conformaram as interações que viabilizaram o acesso aos dados. Isso significa apostar na publicização do processo de fazer pesquisa, potencializando a crítica, a reflexividade e o aprendizado para futuros pesquisadores.

\section{Situando o instrumento que mediou o acesso aos registros das famílias sobre custos}

O questionário foi composto por 56 questões no intuito de se obter um panorama sobre a) as informações sociodemográficas da família e sobre o diagnóstico das crianças e/ou adolescentes; b) eventos referentes à internação nos últimos 12 meses; c) questões econômicas ligadas ao tratamento; d) os tipos de consulta no serviço de saúde em que a criança e/ou adolescente é acompanhado e, e) outras consultas realizadas além do acompanhamento no serviço de saúde.

Assim, o questionário foi construído com vistas a reunir informações para avaliar o custo da doença rara sob a perspectiva de familiares de crianças e adolescentes com condições de saúde complexas e raras, em termos do que as famílias tiveram que fazer para sobreviver, o que mudou nas suas vidas por causa do dinheiro gasto com o tratamento, que tipos de perda financeira ou de outra natureza, e com que tipos de rede poderiam contar para lidar com essa situação.

Pelo grande volume de informações e riqueza de detalhes gerados, foram realizadas anotações das percepções, observações, sentimentos de surpresa, medo e alegria a partir do que foi vivenciado e observado ao longo do processo da pesquisa, devidamente registrados em um diário de campo. Esse processo gerou um círculo virtuoso de registro a partir do diálogo em espaços de supervisão pós-campo onde o acolhimento às experiências vividas, as dificuldades e descobertas foram dialogadas com sugestões de leitura para produção de um conhecimento crítico sobre todo o processo e artesanato de pesquisa.

A aplicação do questionário foi antecedida de uma aproximação da equipe com o campo, da equipe com as famílias que frequentam esse espaço e da própria equipe com o instrumento. Durante duas semanas os pesquisadores estiveram juntos e gradualmente a pesquisa de campo foi assumida por um pesquisador homem, negro com formação em serviço social, o primeiro autor do presente artigo.

Situar quem conduz a pesquisa, acionando suas características a partir do lugar social que ocupa, e o que o diferencia socialmente, visa valorizar os aspectos de reflexividade deflagrados pelo encontro do pesquisador com os sujeitos. Torna-se relevante considerar quem é a pessoa que convida os sujeitos para responderem um instrumento, seu gênero, sua cor e estilo de aproximação.

Os participantes foram 106 familiares de crianças e adolescentes cadastradas nas associações de pessoas com doenças raras referidas a um serviço de saúde especializado situado no Estado do Rio de Janeiro. Neste serviço, recém-nascidos, crianças, adolescentes e mulheres recebem tratamento ambulatorial e hospitalar de alta complexidade. Referência para medicina fetal e gestação de alto risco, conta com várias especialidades, como genética médica, neonatologia, pediatria, fonoaudiologia, fisioterapia, dentre outras.

O trabalho de campo ocorreu entre fevereiro e agosto de 2017. Apesar do interesse em participar da pesquisa, não raro, as datas e momentos da aplicação dos questionários tiveram que ser alterados em função das modificações no estado físico ou emocional das crianças e adolescentes e em respeito aos horários e rotinas das famílias. Por isso, a imersão no serviço de saúde durante sete meses foi fundamental para o mapeamento da rotina de cuidado dirigido à criança e ao ado- 
lescente com condições crônicas de saúde, respeito às rotinas e disponibilidade para conversar ou não, identificar profissionais que pudessem funcionar como facilitadores no contato - enfermeiras, fisioterapeutas, assistentes sociais, residentes, assistentes administrativos e secretárias - apresentando e abrindo as salas de espera dos ambulatórios e as enfermarias. Nesse contexto, foram priorizados diferentes turnos de trabalho (manhã e tarde), de segunda à sexta feira, de forma a obter o maior número possível de participantes para a pesquisa.

Nos casos de internação, o contato se fez prioritariamente pela equipe de enfermagem responsável pelo setor, com o objetivo de pedir autorização à equipe para que os pesquisadores tivessem acesso às famílias. A partir desse consentimento, os pesquisadores apresentavam-se e explicavam os objetivos da pesquisa, assegurando o sigilo e o anonimato das informações, bem como o direito deles de recusa a participar da pesquisa ou interromper sua participação a qualquer momento, sem qualquer prejuízo conforme o Termo de Consentimento Livre e Esclarecido preconizava.

$\mathrm{O}$ acesso inicial às famílias se deu por meio do acompanhamento dos atendimentos ambulatoriais de fisioterapia, sala de infusão, enfermarias pediátricas e em assembleias das associações que organizam ações e reúnem familiares. Essas reuniões aconteceram no período da pesquisa dentro do hospital onde realizamos o campo. São elas: Associação Carioca de Mucoviscidose (ACAM), Associação Nacional de Osteogênese Imperfeita (ANOI) e Anjos da Guarda - Apoiadores aos Portadores de Mucopolissacaridose e de Doenças Raras.

Ressaltamos que este estudo atendeu integralmente as exigências éticas da Resolução no 466/CNS/12, aprovado pelo CAAE.

\section{Navegando e negociando com as relações no ambiente institucional: o jeitinho em ação}

Durante os sete meses de pesquisa foi predominante o protagonismo das mulheres envolvidas com o cuidado de seus filhos, netos e sobrinhos, e que passam a vida peregrinando por diversas instituições, vivendo situações de dúvidas, abandono, medo, estranhamento e incertezas. As mudanças nas rotinas de vida e do cuidado da casa, para assumirem o cuidado cotidiano de crianças e adolescentes cronicamente adoecidos não se faz menor. Partindo de uma visão tradicional do trabalho do cuidado, é das mulheres que se espera a renúncia de conquistas no mundo do trabalho remunerado e da cidadania social, pois se presume que o foco central de suas preocupações continua sendo a casa, enquanto o do homem é sua atuação no mundo público, do trabalho $^{18}$. No caso do cuidado a esse grupo de crianças e adolescentes, viver com uma condição de saúde rara e complexa nos remete a toda uma literatura sobre feminismo, cuidado e deficiência que problematiza as interdependências geradas e as assimetrias de gênero ${ }^{19,20}$.

Para uma reflexão sobre a entrada em campo que nesse caso caracteriza-se como uma instituição hospitalar, faz-se necessário construir estratégias de mediação, autorização e acesso aos sujeitos para o encontro com suas histórias. Isso porque reconhecemos que um hospital caracteriza-se por ser uma instituição de acesso controlado com burocracias para circulação e um reconhecimento de autoridade e competência para dirigir-se as equipes e usuários do serviço. Nessa direção, vale discutir criticamente esse processo com base no conceito de navegação social proposto por Da Matta ${ }^{2}$.

$\mathrm{O}$ autor propõe duas categorias que nos ajudam a entender as interações sociais: o indivíduo e a pessoa. $\mathrm{O}$ indivíduo seria aquele cuja navegação social se dá por vias legais. Ele é o sujeito das leis universais. Já a pessoa é aquela cuja navegação se dá através de suas relações sociais. Segundo o autor, a pessoa seria capaz de operar num sistema legal a partir de "jeitinhos" e arranjos realizados em suas redes de relacionamentos pessoais.

Nesse sentido, o "jeito", para o antropólogo, "é um modo simpático, desesperado ou humano de relacionar o impessoal com o pessoal (...), é um modo pacífico e até mesmo legítimo de resolver problemas"2(p.83). Em síntese, para Da Matta $^{2}$, no Brasil, entre o 'pode' e o 'não pode', encontramos o 'jeito'. Na forma clássica do 'jeitinho', solicita-se precisamente isso: um jeitinho que possa conciliar todos os interesses, criando uma relação aceitável entre o solicitante, o funcionário-autoridade e a lei universal.

O reconhecimento da relevância dessa matriz reflexiva que rivaliza burocracia e "jeitinho" nos leva a assumir a necessidade de construir a relação com o campo de pesquisa e seus instrumentos a partir do modo e/ou estilo de realizar. Faz-se necessário vislumbrar as negociações construídas com as situações e com as famílias pesquisadas no interior desse serviço de saúde.

Em primeiro lugar, a negociação do contato com as famílias, marcada por um estranhamento fundamental é inegável: o de ser um homem negro querendo lançar um olhar para as questões 
relacionadas aos custos não médicos das condições crônicas de saúde de crianças e adolescentes, e ainda por cima dentro de um hospital. Seria um fiscal do INSS, interessado em colocar em risco os Benefícios de Prestação Continuada? Como em um hospital haveria uma pesquisa perguntando sobre bens que a pessoa tinha, as rendas com as quais contava? Em segundo lugar, a negociação com as mulheres/cuidadoras que representaram o maior número de informantes deste estudo, por parte de um pesquisador que reunia características que o aproximavam delas com marcadores de familiaridade.

De fato, um homem entrevistando mulheres também trouxe certas vantagens, na medida em que parecia que determinados assuntos só puderam ser acessados porque um dos pesquisadores era homem. Isso pode ser ilustrado pelo fato de que as mulheres frequentemente recorriam aos sentimentos envolvidos nos relacionamentos $\mathrm{e}$ na família, às tarefas domésticas e do cuidado, ao tempo utilizado e ao esforço desprendido para garantir os direitos dos(as) filhos(as), destacando que os homens eram menos afeitos a isso.

Por outro lado, cabe refletir que a abordagem construída por um pesquisador homem, jovem, negro no interior de uma instituição de saúde permitiu um destaque para uma proximidade a partir dos marcadores cor e geração, sobressaindo sobre o gênero e surpreendentemente provocando uma proximidade e uma identificação com aquelas pessoas que frequentam o serviço. A proximidade parecia se dar a partir de um campo compartilhado de experiências pelos marcadores cor e geração, mas também porque as famílias queriam compartilhar com alguém que não sabia o que era gerar um(a) filho(a) com doença rara uma parte de suas experiências. Esse contato muitas vezes era mediado por emoções que coloriam essa interação de forma impressionista provocando no pesquisador a sensação de que os desafios vividos eram extremamente superiores a capacidade das pessoas gerenciarem seus custos. Ainda que em alguns momentos sobressaem os marcadores cor e geração sobre as relações diferenciais de gênero, não desconsideramos a dimensão interseccional no diálogo entre esses três marcadores na construção das interações e nas negociações do campo de pesquisa.

As famílias recebiam o "convite" para participar da pesquisa mostrando interesse em narrar suas histórias e também pelos futuros resultados do trabalho, com apenas duas recusas: a de uma mãe e um avô. As famílias mostraram-se bastante descontraídas, revelando temas para além das questões pré-estabelecidas no questionário. Um facilitador para o contato e aceite pode ter sido influenciado pelo desconhecimento demonstrado pelo pesquisador sobre suas vidas, ao mesmo tempo pela valorização para explicitarem suas experiências. O fato de ocupar o lugar de pesquisador, um desconhecido da atenção clínica de seus filhos, possibilitava um ambiente onde uma certa surpresa diante dos fatos narrados e um interesse sincero em ouvi-las as estimularam a falarem com desenvoltura, ou mesmo, em alguns casos, autopreencher o questionário de forma a criar um clima de cordialidade e simpatia. Assim, os encontros face a face foram marcados por sucessivos e distintos processos de negociação que sempre respeitaram o real interesse de participação das famílias na pesquisa.

Outro aspecto a ser destacado, diz respeito a identificação da posição profissional no interior daquele espaço. O fato de não utilizar o jaleco branco como um símbolo de distinção ${ }^{21}$ frente aos usuários podia gerar nas equipes e nos próprios familiares uma dúvida quanto a função exercida naquele espaço pelo pesquisador. Ao contrário de outros profissionais de saúde que são reconhecidos seja pelo uso do jaleco, seja por algum uniforme específico, se tornando familiares aos colegas, nós pesquisadores não utilizávamos nenhum elemento que permitisse, num primeiro momento, uma diferenciação de posições seja frente as famílias, seja frente aos profissionais. Essa reflexão sobre os símbolos que mediam a presença e o reconhecimento dos sujeitos no espaço social, não deve ser conduzida sem que situemos o lugar de fala no que diz respeito a cor. Se na maior parte das vezes a pesquisa foi conduzida por um profissional negro essa análise merece ser dialogada a partir desse lugar. Nesse sentido, buscamos apoio em Fanon ${ }^{22}$ na sua reflexão sobre os estereótipos que os corpos melaninados carregam ao transitarem pelos espaços sociais. O autor aponta que o preconceito racial opera como mediador produzindo associações e correspondências do corpo negro com subalternidade e subserviência. Com certa frequência ao circular pelas enfermarias o único pesquisador negro da equipe, e que conduzia as entrevistas, era recorrentemente associado ao pai e/ou acompanhante por alguns profissionais: "o senhor está acompanhando qual criança?" "paizinho, qual o nome do seu filho?". Essa associação, por hipótese funciona reforçando as assimetrias de poder, exclusão e atribuição de um lugar de "estrangeiro", reificando o significado social que o corpo negro carrega ao transitar por espaços institucionais. Aos negros e pardos estão 
reservadas as associações apenas com familiares e acompanhantes, principalmente se nos espaços hospitalares não estiverem com jalecos brancos ou crachás profissionais.

Por outro lado, o fato das famílias entrevistadas serem majoritariamente compostas por sujeitos que se autodeclararam pretos e pardos, fez com que, num primeiro instante olhassem para o negro pesquisador como um provável parceiro e, em nenhum momento houve atribuição de descrédito ou desvalorização por esses sujeitos. Assim, é interessante notar que para além do marcador racial, o desenrolar de uma pesquisa depende de como se dá o encontro entre entrevistador e entrevistado e do que se pretende compreender e investigar.

O fato da pesquisa ter se desenrolado no interior do ambiente hospitalar, nos faz refletir sobre a necessidade de acionar os sentidos da navegação social ${ }^{2}$ para reconhecer que as dimensões do indivíduo e da pessoa estão remetidas a uma ordem a ser negociada ${ }^{1}$. As regras referentes às normas, protocolos, registros, que organizam a burocracia da organização hospitalar, são dialetizadas por um ambiente de regras implícitas, ou registros de mecanismos de seleção e discriminação que permeiam as interações sociais. Esse último conjunto compõe um repertório invisível, mediador das relações entre os atores. $\mathrm{O}$ entendimento do hospital como um sistema, que não se reduz a uma organização burocrática, de regras formais, claras, nos envia a sua dimensão de instituição social que transita entre informalidades, aspectos de influência pessoal e amizades, rivalidades e discriminações para acesso, que caracterizam o conceito de ordem negociada, e o inserem nos universos das relações sociais e seus marcadores de diferença, referidos aos mecanismos de discriminação.

Se o marcador cor esteve em destaque nas discriminações sociais e na atribuição de lugar quando nas entradas nos diferentes ambientes do hospital para acessar as famílias para a pesquisa, devemos apontar o marcador gênero como presente em situações de interação com as mulheres entrevistadas. Aspectos relativos aos sentimentos, com destaque para o ciúme relatado pela mulher frente a possibilidade de ser entrevistada por um homem por telefone, fizeram-se presentes, em uma das entrevistas. A sinalização foi feita porque a entrevistada estava de alta médica e o Transporte Fora do Domicílio a aguardava, e um dos pesquisadores, homem, cogitou a possibilidade de terminar a entrevista por telefone quando ela diz: “olha, quem vai ligar é você?". Ele respondeu: "sim, mas temos mulheres na equipe de pesquisa e uma delas pode fazer esse contato. Você acha melhor?”. Então, com uma expressão sem graça ela diz: "é porque meu marido é muito ciumento, mas você pode ligar”. Não há como deixar de evocar Bonetti e Fleischer ${ }^{23}$, ao se referirem as chamadas saias justas que demandam jogos de cintura em campos onde tinham muita familiaridade, nas interfaces com o movimento feminista, e o fato de serem mulheres. No caso da presente nota, destacamos que sair dessas "calças justas" com total “jogo de cintura” converteu-se também em um grande desafio.

Nesse caso foi preciso acionar símbolos de confiança que passavam por: (a) situar a pesquisa e valorizar as histórias e emoções dos(das) participantes; (b) informar que estávamos inseridos em redes de relações profissionais cuja coordenação era de servidores do serviço, e onde poderiam ser encontrados; (c) permitir escolher se queriam uma pesquisadora mulher para a entrevista. Com isso, fomos possibilitando às famílias se sentirem próximas para falar sobre o custo da doença rara de seu(sua) filho(a), destacando que recordar suas rotinas poderia possibilitar organizar sentimentos e ideias, valorizando sua história. Agindo dessa forma, foi possível através da aplicação de um questionário, diferentemente do que apontam os autores Ramos ${ }^{14}$ e Prodano$\mathrm{ve}^{15}$, valorizar os relatos das famílias sobre quanto gastam com a rotina de cuidados/tratamento de seu(sua) filho(a).

Outro momento "calça justa" esteve referido à necessidade de fazer perguntas sobre o critério Brasil para situar a partir de bens de consumo e remuneração de auxiliares para tarefas domésticas, a faixa de renda da família com suas mudanças antes e depois do diagnóstico da doença rara no(a) filho(a). Nesse momento o jeitinho a ser dado dizia respeito não a navegação social dentro da instituição, mas a capacidade de lidarmos com o constrangimento que uma pergunta difícil poderia causar nos nossos entrevistados. Fazer perguntas sobre custos, renda, valores e perdas evocava um campo de proximidade e intimidade que urgia ser manejado a fim de possibilitar a criação de um ambiente e um rapport de entrevistas que daria condições para acesso aos sujeitos tornando-os confortáveis diante da nossa presença.

Quando perguntávamos às famílias e seus acompanhantes quanto gastavam para ir e voltar da unidade de saúde em cada consulta, notamos, com certa frequência, uma reiteração de expressões de surpresa e espanto, como: "nossa! Eu gasto tudo isso", "caramba eu gasto muito", "uau, nem 
eu sabia que já tinha gasto tudo isso", "muito dinheiro... como consegui pagar?”. Ou ainda, sermos surpreendidos por uma mulher que após ter sido entrevistada em uma semana anterior, nos procurar para entregar anotado numa folha todos os valores precisos de gastos com o tratamento de seu filho.

É importante ressaltar que mesmo havendo um roteiro inicial a ser seguido, existiram variações de uma entrevista para outra, principalmente para que fosse esclarecido que isso não era algo a ser corrigido, ou algo prejudicial ao processo. Mas fazia parte de um movimento legitimo de reencontro com suas histórias de cuidado, e com perguntas que provocavam um dar-se conta sobre perdas, ganhos possíveis, mas muitos desafios. Assim, as pequenas alterações e/ou interrupções ocorreram devido às emoções/reações e respostas dos entrevistados, na interação provocada pela pesquisa. A esse respeito, Teixeira e Figueiredo ${ }^{24}$ ressaltam que:

lidar com as emoções implica ter sensibilidade, saber ouvir e ter uma percepção que vai além da formalidade. É importante saber ler a emoção nas expressões dos sujeitos, nos atos e no tom de voz. Não perceber por perceber, mas a sensibilidade de entender o não-dito, de captar as dimensões, por vezes inconscientes, que o sujeito traz em seu discurso, que fala de suas vivências, de suas sensações corporais. Além do mais, é importante que nos conheçamos e que saibamos expressar nossos sentimentos de modo construtivo, pois o individuo que desconhece suas próprias emoções dificilmente perceberá as emoções do outro ${ }^{24}$.

$\mathrm{Na}$ maioria das vezes fica ausente a referência às conversas com outras pessoas sobre o custo da doença rara de seus filhos, e quando aconteceram estavam referidas ao ambiente doméstico, das redes familiares do núcleo mais próximo. Além disso, nenhuma família entrevistada relatou ter conversado sobre o assunto com profissionais de saúde. Ou seja, na instituição de saúde o esperado é acionar marcadores sobre doença, sintomas, tratamento, exames, e não sobre aspectos que são de sobremaneira importantes para a gestão da vida e da saúde, e que nesse caso são reveladores da dimensão dos gastos diretos e indiretos.

\section{Apontamentos Finais}

Esta nota de pesquisa não buscou fazer um check list das etapas que compõem o trabalho de campo. Longe de ser um roteiro a ser seguido como modelo, é mais uma tentativa de apontar o modo como nos inserimos no interior de uma instituição hospitalar para investigar os custos das famílias com o cuidado das crianças e adolescentes com MPS, FC e OI.

No percurso dessa pesquisa, percebemos que definir o lugar de pesquisador, o papel que ocupa, o que o caracteriza - em termos de suas marcas de cor, gênero, geração - tornou-se fundamental para que se promovesse o contato com as famílias. Ou seja, ao tratarmos do jeitinho como um eixo transversal nesse artigo, o identificamos como de duas ordens; o jeitinho para navegar na instituição e ser autorizado a viabilizar a pesquisa, e o jeitinho de desenvolver habilidades pessoais que suavizassem perguntas sobre temas difíceis, e que nos colocassem diante de memórias de cuidado nem sempre fáceis.

Assim como não se deve ignorar que a presença das famílias em um hospital e o acesso a elas para participar de uma pesquisa exigiu a construção de negociações que muitas das vezes nos faziam construir navegações por meio dos contatos com os profissionais e também com outras famílias que divulgavam a pesquisa e quase que garantiam que o pesquisador era alguém em quem se podia confiar. As negociações construídas durante a realização do trabalho de campo revelam, antes, novos "jeitinhos", novas interações sociais possíveis e, necessariamente, novos dilemas e novas mutualidades, resultantes da interação com as histórias pesquisadas.

Uma das sínteses possíveis sobre a potência de pesquisas que acionam a narratividade a partir de um instrumento voltado para análise de custos pode ser dialogada com a fala de uma mãe entrevistada: "sabe, eu sou muito feliz. Quando vejo o sorriso da minha filha sou a mulher mais realizada do mundo! ... é isso, não preciso de dinheiro .... em relação a isso a gente dá um jeito. Eu sou feliz, minha filha é feliz!". Esse depoimento comparece como um paradoxo que talvez nos coloque diante do seguinte: o importante na relação de cuidado não é necessariamente o custo da mesma para alguns que sobre isso falam. Mas a garantia da presença e da existência dessa pessoa a quem o cuidado é dirigido. Um questionário construído para analisar custos se torna a possibilidade de retomar os valores pessoais e afetivos envolvidos com a gestão da vida e do cuidado. $\mathrm{E}$ por isso navegar em águas raras pode significar ir ao encontro de dilemas, limites, mas também saídas criativas para cuidar e garantir a existência e o direito à saúde. 


\section{Colaboradores}

DS Campos, MCN Moreira, MAF Nascimento participaram da coleta, análise dos dados e revisão crítica do texto.

\section{Referências}

1. Strauss AL. Negotiations: varieties, contexts, processes, and social order. San Francisco: Jossey-Bass; 1978. (The Jossey-Bass social and behavioral science series).

2. Da Matta R. O que faz o brasil, Brasil? Rio de Janeiro: Rocco; 1997.

3. Moreira MCN, Gomes R, Miriam RC. Doenças crônicas em crianças e adolescentes: uma revisão bibliográfica. Cien Saude Colet 2014; 19(7):2083-2094.

4. Mello DB, Moreira MCN. A hospitalização e o adoecimento pela perspectiva de crianças e jovens portadores de fibrose cística e osteogênese imperfeita. Cien Saude Colet 2010; 15(2):453-461.

5. Moreira MCN, Macedo AD. O protagonismo da criança no cenário hospitalar: um ensaio sobre estratégias de sociabilidade. Cien Saude Colet 2009; 14(2):645-652.

6. Moreira MCN, Albernaz LV, Sá MRC, Correia RF, Tanabe RF. Recomendações para uma linha de cuidados para crianças e adolescentes com condições crônicas complexas de saúde. Cad Saude Publica [periódico na Internet]. 2017 [acessado 2017 Nov 25]; 33(11):e00189516. Disponível em: http://cadernos. ensp.fiocruz.br/csp/artigo/293/recomendaes-parauma-linha-de-cuidados-para-crianas-e-adolescentescom-condies-crnicas-complexas-de-sade

7. Universidade de Brasília (UNB). Observatório de doenças raras [página na Internet]. [acessado 2017 Nov 24]. Disponível em: http://rederaras.org/

8. Denis A, Mergaert L, Fostier C, Cleemput I, Simoens S. A comparative study of European rare disease and orphan drug markets. Health Policy (Amsterdam, Netherlands) 2010; 97(2-3):173-179.

9. Harmatz P, Ketteridge D, Giugliani R, Guffon N, Teles EL, Miranda MC, Yu ZF, Swiedler SJ, Hopwood JJ. Direct comparison of measures of endurance, mobility, and joint function during enzyme-replacement therapy of mucopolysaccharidosis vi (Maroteaux-Lamy syndrome): results after 48 weeks in a phase 2 open-label clinical study of recombinant human $\mathrm{N}$-acetylgalactosamine 4-sulfatase. Pediatrics 2005; 115(6):e681-689.

10. Giugliani R, Harmatz P, Wraith JE. Management guidelines for mucopolysaccharidosis VI. Turtelli CM. Manifestações radiológicas da mucopolissacaridose. Pediatrics 2007; 120(2):405-418.

11. Diniz D, Medeiros M, Schwartz IVD. Consequências da judicialização das políticas de saúde: custos de medicamentos para as mucopolissacaridoses. Cad Saude Publica 2012; 28(3):479-489.

12. Bentley P. Understanding cystic fibrosis, improving life expectancy. Nurs Times 1999; 95(43):50-61.
13. Bajpai A, Kabra M, Gupta N, Sharda S, Ghosh M. Intravenous pamidronato therapy in Osteogenesis imperfecta: response to treatment and factors influencing outcome. J Pediatr Orthop 2007; 27:225-227.

14. Ramos MP. Usos de Questionários e Entrevistas na Pesquisa Social: Vantagens e Limitações. In: Fachinetto RF, Lisdero P e Rech CM, organizadores. Metodologia em Ciências Sociais: Práticas, Abordagens e Experiências de Investigação. Jundiaí: Paco; 2016. p. 127-146.

15. Prodanov CC. Metodologia do trabalho científico: métodos e técnicas da pesquisa e do trabalho acadêmico. $2^{\mathrm{a}}$ ed. Novo Hamburgo: Feevale; 2013.

16. Xavier AP. Uma visão antropológica da aplicação de questionários na pesquisa em educação. Educar em Revista 2012; 28(44):293-307.

17. Rostagnol S. Trabajo de campo en entornos diversos: reflexiones sobre las estrategias de conocimiento. Gazeta de Antropología 2011; 27(1):1-14.

18. Hirata H. Mudanças e permanências nas desigualdades de gênero: divisão sexual do trabalho numa perspectiva comparada. São Paulo: Friedrich Ebert Stiftung Brasil; 2015.

19. Diniz D. Feminismo, deficiência e cuidado. O que é deficiência. São Paulo: Brasiliense; 2007. (Coleção Primeiros Passos).

20. Mello AG, Nuernberg AH. Gênero e deficiência: intersecções e perspectivas. Estudos Feministas, Florianópolis 2012; 20(3):635-655.

21. Fontanella BJB, Silva FR, Gomes R. Rituais e símbolos na atenção formal à saúde: o caso do vestuário profissional, na ótica de pacientes da Atenção Básica. Physis 2012; 22(2):507-525.

22. Fanon F. Pele negra máscaras brancas. Salvador: EDUFBA; 2008.

23. Bonetti A, Fleischer S, organizadoras. Entre saias justas e jogos de cintura. Florianópolis: Ed. Mulheres; Santa Cruz do Sul, EDUNISC; 2007.

24. Teixeira ER, Figueiredo NMA. O desejo e a necessidade no cuidado com corpo: uma perspectiva estética na prática de enfermagem. Niterói: EDUFF; 2001.

Artigo apresentado em 27/11/2017

Aprovado em 23/05/2018

Versão final apresentada em 25/05/2018 